\title{
A POLÍTICA GOVERNAMENTAL PARA O ENSINO DE PORTUGUÊS A IMIGRANTES ALEMÃES NO BRASIL: GERADORA E DESTRUIDORA DA EXPERIÊNCIA DA ESCOLA TEUTO-BRASILEIRA
}

José Marcelo Freitas de Luna*

\begin{abstract}
RESUMO: No presente artigo sāo examinadas as açöes governamentais dirigidas à educaçāo dos teuto-brasileiros durante as primeiras quatro décadas do século XX. São apresentadas, com base em fontes primárias, informaçōes sobre o sistema escolar público luso-brasileiro do periodo e discutidas as duas campanhas de nacionalização, através dos seus dispositivos legais e das experiências com o ensino de português desses emergidas no Estado de Santa Catarina. Dada a natureza dessa legislação, a discussão é conduzida sob a perspectiva da educaçāo e dos direitos lingüisticos de minorias.
\end{abstract}

PALAVRAS-CHAVE: Ensino de Português; Historiografia; Imigrantes Alemães; Direitos Lingüisticos.

\section{Introdução}

A té a Primeira Guerra Mundial, o ensino nas zonas de 1 imigração européic em Santa $r$ tarina era feito basicamente em escolas criadas pelos próprios imigrantes. O desenvolvimento desse sistema escolar foi motivado r.nla a.usência do Estado em prover essas populaçōes da educaçao .

- Universidade do Vale do Itajai. 
LUNA, José Marcelo Freitas de. A política governamental para o ensino de português a...

As quatro primeiras décadas do século $\mathrm{XX}$, recorte para o presente artigo, foram caracterizadas por várias reformas, as quais foram consubstanciadas em várias leis e regulamentos. Antes de nos aprofundarmos no periodo em questão, convém resumidamente descrever a Instrução Pública em Santa Catarina no final do Periodo Imperial.

De forma geral, as diversas reformas, empreendidas ao longo do século XIX, não conseguiram tornar eficiente o sistema de ensino em Santa Catarina. O serviço de inspeção escolar era tido como deficiente e os professores continuavam sem a habilitação necessária para prover os alunos de um ensino condizente.

Motivados por esse panorama, a Assembléia Provincial lançou māo, em 1880, de sua prerrogativa, autorizando o Executivo a promover mais uma reforma. A expectativa do Governo, com a chamada reforma de 1881, era imprimir no Sistema Escolar das Provincias as 'idéias' em discussão e prática na época "nos paises mais adiantados".'

Na prática, contudo, após os primeiros cinco anos da reforma, o quadro permanecia inalterado. Os relatórios consultados revelam ter havido uma expressiva falta de fiscalização sobre as atividades de professores e alunos das escolas da Província. Os baixos salários somados à falta de uma politica de qualificação para o docente eram apontados como justificativas para uma demanda inexpressiva pelos cargos de docência e, como conseqüência, para uma dificuldade de manutenção do aluno em sala de aula.

A propósito da evasão de alunos em fase tida como obrigatória, há que se registrar a participação da sociedade como um todo e, em particular, da família. Nos relatórios consultados, encontramos como recorrentes reclamações de professores e dirigentes escolares sobre discursos de pais de alunos, que não viam na permanência na escola vantagem alguma para seus filhos. Lamentando essa questão, o Pre-

I Fala do Doutor Antonio Goncalves Chaves. p. 9. 
sidente da Provincia, Francisco José da Rocha, descreve a atitude mais tipica da época:

Os avós nada sabiam, dizem eles, e viveram; nós pouco sabemos e vamos vivendo e somos solicitados para eleitores e até para autoridades. Nossos filhos, que hão de por força saber mais do que nós, o que virāo a ser? ${ }^{2}$

O periodo Imperial chega, assim, ao seu término exibindo o mesmo quadro educacional do inicio do século. $O$ argumento mais comumente usado para justificar essa inalterância era aquele relacionado à criação excessiva de leis e de outros dispositivos legais.

No que concerne à educação da população de origem estrangeira do Estado, o descrito resumidamente acima pode ser facilmente aplicado. A preocupação do governo com a assimilação do imigrante, através do ensino compulsório de português, contudo, já é registrada durante o periodo imperial.

Pela Lei 1.114 de 30 de setembro de 1886, o Governo vinculou o auxilio financeiro às escolas ao ensino do vernáculo. No seu relatório de 1887, o então Presidente da Provincia, Francisco José da Rocha, revela que a aplicaçāo da lei encontrou resistências diversas em meio aos professores e às autoridades estaduais da época. Segundo ele, não havia, no aparato didático pedagógico existente nas zonas de colonizaçāo, condições para o ensino em bases bilingües.

A concepção adotada na época era a de alfabetizar o aluno inicialmente na sua língua materna (alemāo, italiano ou outra), e só após introduzir o ensino do português. Contudo, essa segunda fase não se concretizava pois coincidia com o momento de retirada dos alunos da escola, por seus pais, em funçāo de atividades ligadas ao trabalho. Dessa forma, o periodo imperial chegou ao seu fim com o problema do ensino da lingua portuguesa para as populações imigrantes inteiramente por resolver.

2 Relatório do Presidente Francisco José da Rocha. p. 96. 
LUNA, José Marcelo Freitas de. A politica governamental para o ensino de português a...

Durante o periodo republicano, a política lingüística governamental voltada aos imigrantes pode ser abordada em termos das duas Campanhas de Nacionalizaçāo de Ensino, as quais foram levadas a efeito por ocasião das duas Grandes Guerras Mundiais.

\section{A Primeira Campanha de Nacionalização: O Programa Orestes Guimarães}

Com a proclamação da Repüblica e a conseqüente adoção de novos valores sociais e politicos, os problemas educacionais vividos pelos Estados continuaram sendo alvo de reformas diversas. Em Santa Catarina, a mais importante dessas reformas, e a que desencadeia a primeira campanha de nacionalizaçāo do ensino, começa em 1911. O Estado estava, desde setembro de 1910, sob o governo do Coronel Vidal José de Oliveira Ramos (daqui por diante Vidal Ramos), natural do planalto catarinense e de familia luso-brasileira de latifundiários e pecuaristas. Seu governo abriu uma dinastia na politica catarinense que determinou os caminhos e a força das ações da nacionalizaçāo no Estado.

Para atacar o problema da educação em Santa Catarina, Vidal Ramos foi buscar em São Paulo, na pessoa de Orestes Guimarães, o modelo de ensino. Esse Estado tinha atingido um nivel de referência em termos de educação, em função de reformas executadas por Bernardino de Campos em 1893. As reformas paulistas, por sua vez. foram muito influenciadas pela linha pedagógica norte-americana, trazida com a fundação da Escola Americana por missões evangélicas dos Estados Unidos. Na área do ensino de português, destacou-se o trabalho da professora Miss Marcia Browne, com o ensino da alfabetizaçāo pelo método analítico.

O paulista Orestes Guimarães chegou a Santa Catarina gozando de todo apoio, do governo e da sociedade em geral, para as ações que ele viria a desenvolver durante os vinte anos que esteve ligado à 
causa da educação do Estado. A responsabilidade atribuida a Orestes Guimarāes era, além da reformulação geral do sistema educacional, principalmente no que se referia às altas taxas de analfabetismo, resolver a questāo da assimilaçāo dos grupos imigrantes.

Nesse sentido, o seu trabalho notabilizou-se por uma ação direta junto às escolas e ao corpo docente em particular, ao qual ele fornecia, pessoalmente, as diretrizes e estratégias de ensino das disciplinas curriculares. Aqui, no entanto, interessam-nos apenas a sua atividade relacionada ao processo de nacionalização e a sua orientaçāo para o ensino do português.

A campanha de nacionalização iniciada por Orestes Guimarāes em 1911, portanto bem antes do periodo mais conflitante causado pela guerra, pode ser caracterizada como um processo gradual de assimilação. Basicamente, esse processo desenvolveu-se pela criaçāo de grupos escolares e de escolas complementares, nos municipios de origem colonial, e pela imposição do ensino de português nas escolas de imigrantes. Respaldou essa estratégia o decreto $n^{\circ} 794$ de 2 de maio de 1914, que reza:

O ensino particular poderá ser exercido livremente, salvo quando for subsidiado pelos cofres públicos, quer estaduaes quer municipaes. Nesse caso devcrá ser ministrado sempre na lingua vernácula (Art. 129).

O principal problema encontrado por Orestes Guimarães para implementação da escola pública em zona de imigraçāo foi a falta de professor com competência lingüistica para o ensino de português. Ele acreditava que o professor adequado para essas escolas deveria ser proficiente nas duas linguas, no português e na língua do aluno e da sua comunidade, principalmente quando o alemão. Sobre isso diz:

O professor que tem de ensinar a crianças que falam uma lingua differente da sua, tem estricta necessidade de saber essa lingua. E o caso dos nossos centros de origem alemã, para onde é preciso enviar professores que falem o idioma alemāo (Guimarães, 1918: prefảcio). 
LUNA, José Marcelo Freitas de. A política governamental para o ensino de português a...

Como encontrar professores, com essa qualificaçāo e disposição para permanecer nos distantes núcleos do interior do Estado a salários módicos, representava uma dificuldade, professores sem o conhecimento da lingua dos alunos ocuparam os cargos abertos nas novas escolas. Contudo, a adaptação dos mesmos ao trabalho com crianças cuja língua o professor não entendia provou ser desapontador para todos os envolvidos.

O professor comumente desistia do trabalho por não conseguir se entender e conseqüentemente transmitir conteúdo aos seus alunos. Além disso, sentia-se segregado socialmente pela falta de contatos com adultos de origem luso-brasileira. No que diz respeito às crianças, o aprendizado do português mostrava-se impossivel, o que levou a uma desconfiança, por parte dos pais, acerca da qualidade da escola pública.

Para resolver o problema da proficiência lingüistica e, conseqüentemente, da habilidade didática do professor para a zona de imigração, Orestes Guimarães introduziu a Lingua Alemã como disciplina curricular na Escola Normal e nas Escolas Complementares do Estado. Essa medida, que foi respaldada por decretos de 1911 e reforçada em 1926, desagradou parte da sociedade catarinense, que já se mostrava indisposta a expressōes das comunidades teuto-brasileiras.

O clima de opiniāo trazido com a $1^{\text {a }}$ Guerra Mundial, que se intensificou com a adesão do Brasil aos Aliados em 1917, fez-se acompanhar de algumas medidas legislativas que atingiram mais diretamente ainda a educaçāo nas zonas de imigração alemā.

Logo em outubro de 1917, a lei estadual 1.187 tornou obrigatórios o ensino preliminar a crianças de 6 a 15 anos e a inclusāo das disciplinas Linguagem, História e Geografia do Brasil, Cantos e Hinos Patrióticos, todas em língua portuguesa. Essa lei, bem como as outras do periodo, abordavam as escolas particulares das zonas de imigração como escolas estrangeiras, desconsiderando o fato de que essas tinham como clientela crianças nascidas no Brasil, que eram, portanto, brasileiras. 
Em 8 de novembro do mesmo ano, o decreto 1.063 determinou a carga horária a ser desenvolvida para cada uma das disciplinas acima, definindo como autorizadas para uso apenas as obras de autores nacionais. Dispôs ainda sobre a reabertura de escolas fechadas pelo argumento de ineficiência quanto ao ensino da lingua portuguesa. Por ineficiência, o decreto referia-se ao ensino ministrado por professores que não falavam "correntemente o português", ou que fizessem uso de material didático não autorizado.

A concessāo de reabertura da escola era dada com base em verificaçāo feita pelos Inspetores Escolares e por professores designados, conforme evidencia o documento abaixo transcrito:

Tendo Amadeu Baeder, professor particular em São Pedro, Colonia Olsen, municipio de S. Bento e Ludwig Neuman, idem das Escolas de Cedro Grande e Aguas Claras, no municipio de Brusque, pedido licença para reabrir as suas Escolas, de accôrdo com o Decreto $\mathrm{n}^{\circ}$ 1063, de 1917, designe as professoras Martha Tavares Alves e Ilsa Tavares para verificarem si o primeiro daquelles mestres fala correntemente o Portuguez e os professores Guilherme Wiethorn Filho e Laura Garcia para identica verificação do segundo dos mesmos mestres. (Minutas da Instruçāo Pública, 1918 e 1919: 23)

Para as escolas, ajustar-se às exigências legais de reabertura foi bastante problemático. Encontrar professores competentes e material adequado em meio a um sistema de ensino público precário constituia-se quase uma impossibilidade. As escolas tinham que convencer as autoridades locais que o curriculo dispunha de tempo suficiente para Português, História e Geografia.

Por outro lado, conseguir passar nos exames introduzidos era muito dificil para muitos professores. Boa parte deles era formada por imigrantes nascidos na Alemanha, que não tinham tido a preocupação em adquirir a cidadania brasileira. Invariavelmente, os examinadores mostravam-se relutantes em permitir que 'inimigos' ensinassem. Muitas escolas permaneceram fechadas permanentemente, 
LUNA, José Marcelo Freitas de. A política governamental para o ensino de português a...

o que implicou o afastamento de milhares de crianças teuto-brasileiras da educação formal.

Durante o periodo de guerra, todos os esforços de assimilaçāo progressiva foram, aos poucos, sendo confundidos com incidentes relacionados ao fechamento de escolas, pedidos de puniçāo de professores, que clandestinamente continuavam a ministrar aulas em suas residências, e, ainda, com alguns casos mais esdrúxulos como o abaixo resumidamente descrito.

Conforme determinação de V. S. em telegrama de hontem, passo a relatar o ocorrido em minha casa ou antes, na sala da Escola por mim regida, no dia 15 do corrente. Roberto Hoffman, professor allemão do povoado de Matto-Preto, sendo constrangido a fechar sua escola, em virtude das ordens do governo logo ao declarar-se existente o estado de guerra entre o nosso paiz e a Allemanha, resolveu tomar licçōes de portuguez para reabrir suas aulas. (...) Ontehontem, como de costume, Hoffman apresentouse em minha casa a'hora da licçāo, isto é, às $161 / 2$ horas; fil-o entrar, mas imediatamente foi-me elle dizendo que nāo desejava mais aprender a lingua portugueza e, pelo contrario, desejava desaprendel-a porque sua patria, a Allemanha, já tínha vencido a todos os seus inimigos ...O Brazil, vencidos os seus alliados, seria obrigado a pagar uma forte indenisação de guerra, e, nāo tendo dinheiro para fazel-o teria forçosamente de dar uma parte do seu território - O Estado de Santa Catharina - De agora em diante era pois prohibido fallar-se em São Bento, outra linguagem nāo a allemã e dirigindo para a porta exclamou, num grande transporte de alegria e batendo nos peitos: "Oh! a lingua allemã é a lingua da gloria; ella será a lingua universal: Eu fui e sou soldado allemão e sei o que vale a Allemanha". (...) Julgando ser não só um desacato a mim e à minha profissāo, como também um pesado insulto lançado por esse individuo à face de minha cara pátria, nāo tendo na comarca autoridade policial e achando-se ausente o snr. Chefe Escolar, resolvi procurar o exmo snr dr. Juiz de Direito da Comarca, que me aconselhou telegraphasse a V. S. participando o ocorrido e pedindo providencias (...). (Oficios da Instrução Pública, 1918: 22)

Orestes Guimarāes atravessa esse periodo convencido de que suas estratêgias de assimilação progressiva não podiam sofrer com o 
clima de antipatia e aversão ao alemão trazido pelo conflito bélico. No seu relatório de 1918, ele se defende de comentários contrários a sua politica de manter o ensino de alemão nas escolas de formação de professores, dizendo:

\begin{abstract}
O estado de guerra actual não modificou o problema pedagógico: a lingua, as tendencias e os habitos continuam a ser os mesmos nos alludidos centros, (...) $\mathrm{Si}$, para ensinar o portuguez a quem só fala o alemão, o professor tem necessidade de conhecer esta ultima lingua, bem è que se conserve nos programmas da Escola Normal e escolas complementares o ensino do alemão, não obstante o jacobino modo de pensar dos que entendem que apprender uma certa e determinada lingua é homenagear a nação que a fala! (Guimarães, 1918: prefäcio).
\end{abstract}

Além de posicionamentos como esses enfatizando a sua atitude em relação ao ensino do português feito por professor bilingüe, os principios metodológicos difundidos por Orestes Guimarāes podem ser encontrados em apenas duas publicações. A primeira, publicada em 1918, carateriza-se como um Termo de Visita de Verificação, feita a um grupo escolar em Blumenau. A segunda representa um Programa de Ensino, desenvolvido por ele em 1926, especificamente para as escolas das zonas coloniais.

Nessas duas fontes, apesar do periodo de oito anos que as separa e das diferentes clientelas que visam, percebemos que Orestes Guimarães baseou-se nos mesmos objetivos para elaborar as estratégias de ensino recomendadas para a lingua portuguesa.

Partindo da evidência de que quase a totalidade das crianças nas regiões de imigração não falava ou compreendia o português, ele estrutura o programa ampliando a carga horária desta disciplina e propondo estratégias de interdisciplinaridade, como ele mesmo enfatiza: "cada parte do programa, convenientemente processada, CONSTITUE EXCELLENTE ELEMENTO PARA O DESENVOLVIMENTO DA LINGUAGEM (Guimarães, 1918: 3)". Os programas são organizados 
LUNA, José Marcelo Freitas de. A política governamental para o ensino de português a...

por ano escolar e por habilidades lingüisticas, no caso leitura e linguagem oral e escrita.

Para leitura, ele sugere atividades que se fundamentam, segundo cle, numa visão eclética, situada entre a corrente tradicional de alfabetização pelo método sintético e a então recente corrente baseada no método analitico. Nesse sentido, Orestes Guimarães sugere, para os primeiros anos, a estratégia de apresentação, no quadro negro, de palavras isoladas, seguidas de repetição e tradução para retençāo ${ }^{3}$ do significado. Após os exercicios de tradução, as instruções são no sentido de decomposição das palavras em sillabas, com ênfase na exatidão da pronúncia das mesmas.

O passo seguinte é a introdução dos alunos às cartilhas, para as quais as mesmas estratégias de tradução e decomposição de palavras e sentenças são recomendadas. Para os demais anos, as mesmas atividades de leitura são reproduzidas e sua verificação ou correção vai adquirindo um caráter punitivo, conforme indica o trecho abaixo:

$\mathrm{Na}$ aula após o recreio, o professor lê o capitulo, chama os alunnos, alternadamente, manda-os ler em voz alta, corrige a pronuncia, pontuaçāo e accentos da phrase; ordena que os alunnos preparem o capitulo em casa (...) o professor chama todos os alunnos, deixando sem recreio ou presos depois da hora aquelles que não tenham preparado as liçōes. (Guimarāes, 1918: 5)

No que concerne ao ensino da linguagem oral, os programas de Orestes Guimarães elegem atividades orais como a base para o desenvolvimento da escrita. Para justificar a necessidade de um tratamento mais elaborado dessa habilidade, o autor faz referências a teorias de aquisição da linguagem materna e a sua relação com o processo de aprendizagem de uma segunda lingua.

3 O uso de retençáo, embora possa parecer estranho e deslocado, substitui memorização. termo que carrega uma associação direta com uma metodologia /abordagem especifica. 
Para o desenvolvimento dessa habilidade, novamente sugere o emprego escrito de palavras isoladas no quadro negro, pelo professor, e a formação de sentenças nas três formas, seguidas de tradução para o alemão pelo aluno, conforme mostra o exemplo abaixo:

Entre essa madeira, há um enorme madeiro. Entre a grita da maruja, ouviu-se o grito do commandante. Saia por essa porta e vá ao porto. A agua do meu banho estava com banha (...) (Guimarães, 1918: 13).

Além desses exercícios de repetiçāo e tradução de palavras e sentenças isoladas, o autor recomenda o que se pode chamar de tópicos de conversação ou, em suas palavras, 'palestras em forma de diálogos', sobre assuntos ligados à escola, ao municipio, ao pais, ao asseio do corpo, das casas, etc. Contudo, ele nāo fornece as estratégias para condução desse exercício; apenas menciona que os termos devem ser abordados por idéias gerais e que os alunos devem se expressar em lingua portuguesa.

Por fim, para a linguagem escrita o autor reivindica a integração ou ensino intercorrente das três habilidades. Nessa linha, sugere atividades de cópia e ditado das palavras, das sentenças e passagens dos livros de leitura que foram trabalhados oralmente. Da mesma forma, os exercícios de decomposição silábica são recomendados como atividade escrita.

Para o segundo ano, essas atividades são mantidas em sua natureza, sendo apenas ampliadas no que diz respeito ao tamanho dos textos. É só nessa parte do programa do segundo ano que o ensino da gramática é contemplado, através de exercícios sobre flexões e derivação, com base em palavras potencialmente já conhecidas pelos alunos, como essas abaixo:

projectil, festim, ferrugem, ferradura (...) (Guimarães, 1926:16)

No terceiro ano, o ensino da gramática ganha todo espaço das três habilidades de forma explicita, tendo como estratégia de trabalho

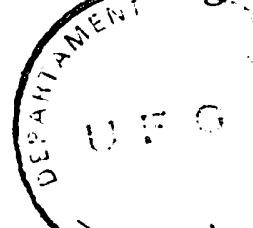


LUNA, José Marcelo Freitas de. A politica governamental para o ensino de portuguès a...

as mesmas recomendadas para os outros assuntos dos primeiros anos, conforme ilustra o extrato abaixo:

linguagem oral: $1^{\circ}$ Conjugaçāo pratica, em todos os tempos, dos verbos auxiliares (tradução de todos os tempos conjugados) (...) $4^{\circ}$ Conhecer, praticamente, os adjetivos demonstrativos possessivos, conjunctivos; os pronomes pessoais e as suas variações (decorar e traduzir) linguagem escrita: $1^{\circ}$ Escrever, em todos os tempos, os verbos auxiliares (...) $4^{\circ}$ Escrever, systematizadamente, os adjectivos e pronomes estudados (Guimarães, 1926: 20-21).

\section{A Segunda Campanha de Nacionalização: O Programa Liga Pró-Língua Nacional}

Para boa parte da populaçāo teuto-brasileira, o final da guerra não trouxe as suas instituiçōes de volta ao clima de normalidade. Em Santa Catarina, muitas escolas continuaram a ser perseguidas, através de legislação restritiva adicional criada após o armisticio.

Em setembro de 1919 , a Lei $n^{\circ} 1.283$ reforçou o previsto na Lei 1.187 de 1917, definindo como escolas estrangeiras aquelas cuja instrução em uma ou mais disciplinas fosse dada em outra lingua que não o português, independente da nacionalidade ou local de nascimento do professor. Um mês mais tarde, muitas escolas foram fechadas em Santa Catarina, por causa de supostas violaçōes dessas exigências. Em janeiro de 1920, a Lei $n^{\circ} 1.322$ especificou que as escolas teuto-brasileiras deveriam oferecer vinte e quatro periodos de instruçāo, em lingua portuguesa, de Leitura, Escrita, História, Geografia, Música e Civismo. Além disso, todos os documentos escolares deveriam ser escritos em português.

Toda essa legislação continuava a refletir a atitude dos governantes de tendência nativista, os quais reportavam tal sentimento e apoio à obra de nacionalização nos discursos e nos diversos documentos do periodo entre-guerras. $O$ tom usado nos discursos sobre 
as escolas particulares era geralmente de denúncia contra a suposta falta do ensino de português nas escolas teuto-brasileiras e de outras origens estrangeiras. Isto era tomado, pela sociedade em geral, como argumento de sustentaçāo da segunda campanha de nacionalizaçāo, que se desenhava ao longo da década de 30 . Os textos, abaixo transcritos parcialmente, ilustram essa atitude:

(...) convêm salientar que uma bôa parte das escolas ruraes coloniais se acha regida por professores que por falarem mal, ou nāo falarem a lingua vernácula, não podem satisfazer as justas necessidades da nacionalização do ensino primário, assumpto esse que em Santa Catarina se reveste da real importância e ao qual os seus governos vèm de anos dispensando a maior atençāo $(. . .)^{+}$

(...) O trabalho nacionalizador nesta unidade da federação tem de ser ativo, constante e de grande vigilancia a fim de que se não crie um corpo estranho dentro da brasilidade, o que constituiria uma vergonha para os nossos brios de nação nova, que tem de formar-se una e indivisa, e impedir que se desenvolva no seu organismo civico um quisto de estrangeirismo degenerador $(. . .)^{5}$

Caracteriza-se, assim, como constante nos documentos oficiais relacionados à segunda campanha de nacionalização, o reconhecimento explicito dos governantes desse segundo periodo acerca da omissão do governo em prover as comunidades imigrantes da educação pública devida. Contudo, merece destaque o fato de que por provisão todos os documentos reclamam escolas onde o ensino de português fosse desenvolvido de forma a promover a assimilação dos imigrantes. Ao discutir o papel do governo nesse contexto, o Superintendente Geral de Ensino, Sebastião de Oliveira Rocha, destaca em seu Relatório de 1939:

Qual o ponto inicial da civilização? É sem dũvida a escola primária. Era de prever-se que os colonos ao formarem um nú-

4 Relatório. Apresentado ao Dr. Manuel da Nöbrega e ao Snr. Dr. Cid Campos.

5 Relatório. Apresentado pelo professor Barreiros Filho. 
LUNA, José Marcelo Freitas de. A política governamental para o ensino de português a...

cleo, tratassem logo de organizar a sua escola para manter aqueles principios (...) Se houvesse precaução dos nossos dirigentes em dotar cada centro de imigração com uma escola perfeitamente aparelhada para ministrar os primeiros ensinamentos de vernáculo, hoje não teriamos de ouvir censuras aos nossos poderes, pela sua negligência no tocante ao ensino do Português aos filhos de imigrantes. ${ }^{6}$

Após a saida de Orestes Guimarāes, por sua morte, da campanha de nacionalização, em 1930, o sistema escolar do Estado, no tocante ao ensino de português nas zonas de imigração, começou, aos poucos, a ser guiado unicamente por dispositivos legais. O Decreto $n^{\circ} 58$ de 28 de janeiro de 1931 aborda as escolas particulares ainda como estrangeiras e determina que todas as disciplinas deveriam seguir o programa das escolas públicas do Estado. Ao impor o programa de Português da escola pública às escolas teuto-brasileiras, o educador / legislador continuou a determinar a necessidade de o Português ser tratado como lingua nacional, devendo ser ensinada indiferentemente com estratégias de lingua materna.

Com a instalaçāo do Estado Novo, uma nova campanha de nacionalização passou a desenvolver-se, tendo como alvo novamente as escolas de zona de imigração estrangeira. Assumindo que o problema da assimilação não havia sido resolvido pela flexibilidade das leis anteriores e, segundo um dos mentores das leis da segunda nacionalização, por Ivo d'Aquino, "concepções errôneas e até certo ponto ingênuas" (Aquino, 1942:140), a segunda campanha encontra, no regime autoritário do Estado Novo, o clima adequado para leis impondo uma assimilação coercitiva e imediata.

Três decretos federais podem ser apontados como exemplos de autorização ao Estado a infringir os direitos educacionais e lingüisticos de suas populações imigrantes.

O Decreto-Lei $\mathrm{n}^{\circ} 868$ de 18 de novembro de 1938 criou, no Ministério de Educação, a Comissão Nacional de Ensino Primário.

- Relatório. Pelo Professor Sebastiāo de Oliveira Rocha. 
Essa tinha como um dos seus objetivos a definição de ações de nacionalização integral do ensino primário de todos os núcleos de população de origem estrangeira.

O Decreto-Lei $\mathrm{n}^{\circ} 1.006$ de 30 de dezembro de 1938, por sua vez, normatizou o livro didático, proibindo o uso no ensino primário de publicações não escritas em lingua nacional.

Finalmente, o Decreto-Lei $n^{\circ} 3.580$ de 3 de setembro de 1941 ratificou o disposto no decreto acima, enfatizando a proibição de importação de livros didáticos para uso no ensino primário, bem como a produção, no Brasil, de livros escritos total ou parcialmente em lingua estrangeira. A proibição compreendia também jornais, periódicos, revistas de igreja, almanaques, literatura devocional e até traduções de clássicos da literatura portuguesa e brasileira.

Em Santa Catarina, a interpretação e desdobramento dessas leis causaram um impacto bastante traumático para a população teuto-brasileira. Embora a campanha de nacionalizaçāo houvesse começado em 1911, com o trabalho de Orestes Guimarães, os objetivos assimilacionistas do Governo nāo tinham sido alcançados. Contribuia igualmente o fato de politicamente o Estado näo dispor de uma liderança positivista mais forte, o que fazia sentimentos nativistas prevalecerem e se intensificarem com o clima trazido pela Segunda Grande Guerra.

Explorando esses fatores, a propaganda anti-alemã no Brasil continuava a identificar Santa Catarina como um estado vulnerável à insubordinação teuto-brasileira e à adesão à Alemanha. Soma-se a todos esses fatores o fato de a liderança politica no Estado ter, durante esse periodo, estado nas mãos da familia Ramos, que exibia tendências nativistas claras. $O$ Governo, conseqüentemente, sentia-se mais preocupado e motivado em erradicar qualquer fonte de identificação com o Pais ou com a comunidade inimiga. Em uma entrevista sobre as eleiçōes municipais de 1936, Nereu Ramos, então governador, comenta sobre a derrota do seu partido para os integralistas nos municipios de colonização alemã: 
LUNA, José Marcelo Freitas de. A politica governamental para o ensino de português a...

(...) Em todos os municipios em que o integralismo venceu, predomina o elemento alemāo. A bandeira não é Plinio Salgado, mas sim Hitler. (...) Creio que está na hora de se iniciar uma enérgica obra nacionalizadora nos municipios em que a colonização alemā não quer adaptar-se à vida brasileira ...Isto significaria: estacionar mais tropas nas zonas de imigração alemā, para que a mistica do militarismo alemão tenha, em nossas casernas, um derivativo e os elementos teuto-brasileiros aprendam a integrar-se na vida brasileira (citado em Gertz, 1987: 112).

A hipótese de vinculação da nacionalização ao clima político interno do Estado, e nāo somente com o clima trazido pelas guerras encontra sustentação quando da consideração detalhada das leis estaduais. Como mostramos acima, o governo estadual de Santa Catarina legislou nesse sentido durante boa parte do periodo que separou as duas Grandes Guerras. Mas é, sem dúvidas, a partir da instalação do Estado Novo e da aproximação da Segunda Guerra Mundial, que uma segunda campanha de nacionalização se instala, reelegendo a escola das comunidades imigrantes como seu alvo de ataque. Segundo Aquino (1942), a primeira campanha havia favorecido a manutenção de escolas vistas por ele como "desintegradas do sentimento nacional e atentatórias à comunidade moral e política da naçāo" (Aquino, 1942: 26). Especificamente, dois decretos podem ser citados como exemplos do grau de imposição e proibiçāo que marcou essa campanha.

O Decreto-lei $n^{\circ} 35$ de 13 de janeiro de 1938 proibiu o uso de nomes estrangeiros em todos os estabelecimentos do Estado, inclusive os escolares. O decreto previa a pena de fechamento de escolas que, de alguma forma, exibissem uma denominação que não fosse em lingua nacional.

O carâter proibitivo no que diz respeito aos direitos lingüísticos e educacionais da comunidade teuto-brasileira fica mais evidente, contudo, no Decreto-Lei $n^{\circ} 88$ de 31 de março de 1938, que estabelece as normas relativas ao ensino primário em escolas particulares. $O$ 
decreto obrigava a escola particular, durante a primeira campanha abordada como estrangeira, a tirar uma licença do Governo para seu funcionamento. A concessão dessa, por sua vez, era vinculada, segundo o decreto, ao cumprimento de muitas exigências, entre outras:

1 - prova de serem brasileiros natos os professores da lingua nacional, geografia, história da civilização e do Brasil e de educação civica e moral, em todos os cursos. (...) 10 - prova da capacidade didática dos professores: (Art. $\left.4^{\circ}\right)($ (..) 1 - dar em lingua vernácula todas as aulas dos cursos pré-primário, primário e complementar, inclusive as de educaçāo física, salvo quando se tratar de idioma estrangeiro (...) 3 - usar exclusivamente a lingua nacional quer na respectiva escrituração, quer em taboletas, placas, cartazes, avisos, instruçōes ou dísticos, na parte interna ou externa do prédio escolar (Art. $7^{\circ}$ ). (...) Os mapas, fotografias, estampas, disticos ou emblemas, assim nas salas de aula, como em qualquer outra parte do prédio escolar, não poderão perder o caracteristico de brasilidade. (Art. $\left.8^{\circ}\right)(\ldots)$ Excetuados os estrangeiros que sejam hóspedes oficiais do Governo do Estado, nenhum orador, ou conferencista, poderá expressar-se, nas reuniōes ou comemoraçōes escolares, senāo em lingua nacional (Art. 13). (...) Fechar-se-á definitivamente o estabelecimento, quando (...) ministrar o ensino de lingua estrangeira a crianças que não tenham o curso primário no idioma nacional (Art. 19).

Por esse nivel de exigência, muitas escolas foram fechadas e impossibilitadas de reabertura. Outras poucas permaneceram na clandestinidade desenvolvendo o ensino com base em seus recursos. Com o agravamento do quadro de perseguição gerado pela Guerra, contudo, todas as escolas teuto-brasileiras foram fechadas, sendo algumas assumidas pelo Estado e transformadas em escolas públicas.

A questão referente à resistência dos pais em matricular os seus filhos nas escolas públicas foi também resolvida, paralelamente, por força do Decreto-Lei $n^{\circ} 301$ de 24 de fevereiro de 1939, o qual instituiu a quitaçāo escolar. $O$ decreto previa implicaçōes de caráter punitivo como multas e outras privações legais. 
As legislaçōes e açōes desse periodo foram também respaldadas pela imprensa catarinense de tendência governamental. Como na primeira campanha, os jornais exploraram a nacionalização das áreas de colonização estrangeira do Estado, através de matérias que valorizavam a açāo do governo na mesma medida em que condenavam o comportamento das comunidades imigrantes, sobretudo as de origem alemã. Esse apoio à causa de nacionalização naturalmente intensificou-se com a deflagração da $2^{\mathbf{a}}$ Guerra, conforme evidencia uma amostra das reportagens publicadas entre os anos de 1938 a 1942, cujas manchetes reproduzimos abaixo:

1938: "Problema Inquietante: Brasileiros que nāo falam a nossa lingua"

1939: "A Campanha de Nacionalização e o Exército"

1940: "Maior será o estagio para os que não falarem correntemente o portuguēs"

1941: "A Praga Nazista no sul"

1942: "Nāo. Não pode ser catarinense quem procede assim" (Jornal O ESTADO, 22/01/38, 10/04/39, 02/05/40, 31/12) $41,21 / 08 / 42)$

Alguns dos livros sobre a questāo da colonizaçāo do Brasil, publicados no mesmo periodo, exploram o assunto através de denúncias semelhantes, as quais se revestem de total apoio às açōes de nacionalizaçāo empregadas. Ramos (1939) mostra-se como um bom exemplo desse tipo de publicação:

Os imigrantes, aproveitando a insidia reinante, organizavam, então, as suas escolas particulares, nas quais os seus filhos aprendiam o idioma e as tradiçōes dos seus maiores (...) As ideologias malsãs, numa diabolica infiltração, estavam pouco a pouco, corroendo o organismo colonial, numa perigosa ameaça à sua organização política e social. (...) Uma das mais acertadas medidas foi a localização, ali, de batalhōes do nosso Exército. (Ramos, 1939: 29-30)

Para respaldar o Decreto 88, o governo baixou o Decreto-Lei $\mathrm{n}^{\circ}$ 124 em 18 de junho de 1938, criando a Inspetoria Geral das Escolas 
Particulares e Nacionalização do Ensino. Entre outras atribuiçōes do Inspetor Geral estava: "propor a Superintendência Geral do Ensino as medidas que, para êsse fim (nacionalização do ensino), julgar necessárias, especialmente quanto ao afastamento de professores e interdição de estabelecimentos escolares que transgridam aquelas leis" (Art. $2^{\circ}$ ).

A inspetoria, criada pela lei, acima foi primeiramente ocupada por Luiz Sanches B. da Trindade, que já havia trabalhado anteriormente na causa da nacionalizaçāo, como integrante da equipe de Orestes Guimarāes. A atuaçāo dessa Inspetoria foi marcada, basicamente, por fechamento de escolas, suspensão e afastamento de professores. Contudo, deve-se ao professor Trindade a criação da Liga Pró-Lingua Nacional (daqui por diante Liga(s)).

Embora tenham sido propostas para todas as escolas públicas do Estado, as atividades das Ligas estiveram mais relacionadas àquelas escolas de regiōes de imigraçāo. As Ligas foram criadas com o objetivo expresso de fomentar nos alunos o interesse pela defesa e difusāo dos valores nacionais. Nesse sentido, as atividades propostas pela Inspetoria envolviam a valorização e, em alguns casos, a exaltaçāo de todos os traços da cultura e do Estado brasileiro, entre outros, a lingua portuguesa.

Com a orientação de professores, supervisão da direção da escola e, freqüentemente, com a fiscalização do próprio Inspetor, os alunos mais adiantados eram incumbidos da função de desenvolver nos alunos descendentes de imigrantes as habilidades lingüisticas e uma atitude positiva em relação ao português. $O$ ensino do vernáculo implicava, contudo, a proibição do uso da lingua materna do aluno, conforme evidencia a seguinte instrução:

(...) Sāo deveres do presidente: (...) contribuir, com o seu melhor esfôrço, no sentido de que não se fale outra lingua, quer dentro do estabelecimento, quer fora, que não seja a Nacional. quando em zona de colonização estrangeira. (Instruções Liga Pró-Lingua Nacional, p. 123). 
LUNA, José Marcelo Freitas de. A política governamental para o ensino de português a...

Para o desenvolvimento de suas atividades, os alunos eram instruidos a confeccionar álbuns, com fotografias de pessoas ligadas à história do Brasil e de paisagens tipicamente brasileiras. Esses álbuns eram usados como recurso didático pelos alunos-professores durante o recreio, conforme a orientação recebida:

(...) os alunos procurarāo estar em contato com os que tèm dificuldade de pronúncia, principalmente nas zonas de colonização, procurando corrigir os seus erros. Tambèm levarāo os álbuns já organizados e procurarão reunir um número de colegas para mostrar-lhes e comentar os assuntos ali em fóco (op. cit. acima p.124).

Além dessa atividade, as Ligas também eram incentivadas a manter correspondências entre si. Objetivava-se, com isso, a troca de fotografias e informaçōes culturais, além da prática de redaçāo em português.

Como já sugerido, o trabalho das Ligas era sistematicamente acompanhado pela Inspetoria Geral, através de visitas às escolas e, mais comumente, por correspondências enviadas às lideranças. A leitura dessas correspondências revela que o interesse da Inspetoria e, por extensāo, do Governo resumia-se à difusão do mesmo nacionalismo exacerbado, refletido nos dispositivos legais já discutidos. Dito de outra forma, em nenhuma das cartas analisadas encontra-se referência à preocupaçāo com o desenvolvimento do ensino do português. Esse argumento pode ser respaldado pelas cartas escritas pelo professor Trindade, como a que resumimos abaixo:

(...) Nestes ALBUNS devem figurar coisas de nosso amado Brasil. Para maior conhecimento de nossos homens, lembro a vocês que cada sala de aula tenha um nome de um brasileiro ilustre (...) As vidas dêsses vultos nacionais devem ser estudadas pelos alunos (...) TUDO PELA GRANDEZA DO BRASIL. (Carta $n^{\circ}$ 1. In: Relatório do Departamento de Educação, 1940: 8)

Em outra carta, enviada a uma outra Liga no mesmo ano, o caráter coercitivo do periodo fica mais evidente: 
Rev. ANPOLL, n. 8, p. 59-86, jan./jun. 2000

(...) Escrevi para vocès, dei instruçōes sôbre diversos serviços a serem organizados. Apezar disso vocês se mantêm num silêncio que não posso compreender. Já fiz sentir essa falta às autoridades do Estado. Breve fiscalizarei êsse educandảio para verificar 'in loco' as causas deste desinteresse pelas cousas nacionais (...) (Carta $n^{\prime \prime} 188$. In: op. cit.: 37)

As respostas por parte das Ligas, por sua vez, sugerem que o objetivo de desenvolvimento do nacionalismo fora bem assimilado pelos alunos. Em carta enviada ao mesmo Inspetor em 1939, uma aluna de Joinville escreve sobre sua motivação com o trabalho nacionalizador naquela cidade, que, como Blumenau, era tida como um quisto étnico. Ela diz:

(...) Agradecemos sôbretudo a confiança que em nós depositou: seremos seus pequenos ajudantes na grande e nobre obra de nacionalizaçāo (...) Ansiosos esperamos breve a sua visita e receber umas palavras de reconhecimento pelos nossos esfôrços e para V. Excia se convencer que tambèm a mocidade joinvillense defato é e quer ser de todo coração, filhos dessa grande e querida pátria (...) (Carta $n^{\circ}$ 57. In: op. cit.: 15)

Diferente das cartas da Inspetoria, as das lideranças das Ligas trazem algumas referências ao desenvolvimento da aprendizagem do português por parte dos alunos das comunidades estrangeiras. Contudo, pode-se observar também que o objetivo de tornar-se proficiente no vernáculo confunde-se inteiramente com o ideal do nacionalismo apregoado pelo Governo. Esse argumento pode ser ilustrado pela carta de uma aluna de Blumenau, escrita ao Inspetor em 1939:

(...) Desde $1^{\circ}$ de março que frequento a escola Sagrada Familia. Já adiantei nos estudos principalmente na percepçāo da lingua portuguesa. Para mim è um grande prazer estudar e sei que é o nosso dever falar bem a lingua nacional, pois só assim podemos amar a nossa Pátria (...) (Carta $n^{\circ}$ 58. In: op. cit.: 16)

Da mesma forma, o sucesso na aprendizagem do português é medido e anunciado pelo grau de abandono ou mesmo desprezo que 
LUNA, José Marcelo Freitas de. A política govemamental para o ensino de português a...

o aluno passava a ter em relação a sua lingua materna. Em todos os relatórios consultados, há referências como estas que citamos a seguir:

(...) Para provar ainda o bom exito do nosso trabalho que, dia a dia, se torna mais proficuo, citarei alguns fatos presenciados por essa inspetoria. (...) O sr. Geitzhauer, que havia retirado suas filhas do colégio "Santos Anjos" visitado por essa inspetoria que lhe pediu explicações sôbre os motivos que o levaram a tal ação respondeu-me: Minhas filhas näo querem mais falar o alemāo, só o português. Nesses dias eu estava lendo o "Deutche Zeitung" e a mais velha chegou-se e perguntou-me em português: $O$ que está lendo pai? Disse-lhe em alemão: "São cousas sôbre a grande Alemanha" - ela respondeu-me: "Isso não me interessa" (...) Vemos dai que felizmente as crianças ajudam a nacionalizar. (Relatório do Departamento de Educaçāo, 1940: 10)

\section{Considerações finais}

A partir de uma breve exploraçāo da produção deixada por Orestes Guimarāes, percebemos que a sua ação nacionalizadora esteve voltada para a assimilaçāo do imigrante, através de uma exposiçāo gradual e freqüente ao ensino sistemático da lingua portuguesa.

Percebe-se que a sua formaçāo de educador foi suficiente para entender que essas escolas deveriam ser providas de um programa e estratégias de ensino diferenciadas daquelas escolas de regiāo essencialmente luso-brasileira. Evidenciam essa noção os esforços feitos por ele para a formaçāo e contrataçāo de professores bilingües e suas visitas e palestras em escolas de todo Estado. No que concerne aos principios por ele adotados para o ensino da lingua portuguesa, verifica-se a orientação dos treinamentos dados pela professora Miss Browne, em São Paulo, durante a primeira década do século, a ele próprio e a sua esposa, professora Cacilda Guimarães, que o acompanhava nas visitas e palestras dadas pelo Estado, divulgando o método analitico de alfabetização. 
Foi com base nas estratégias do método analitico que Orestes Guimarães passou a orientar o ensino da leitura nas escolas de todo o Estado, incluindo as escolas e grupos escolares criados por ele nas zonas de imigração. Em outras palavras, excetuando as tentativas de contratação de professores bilingües e o aumento da carga horária de Lingua Portuguesa, as estratégias de ensino por ele recomendadas para o ensino de português nas escolas de imigrantes coincidem com aquelas igualmente por ele indicadas para escolas de outras regiōes.

Mais precisamente, nāo se registra a inclusāo da lingua materna dos alunos no curriculo escolar, nem se percebe uma preocupação, por parte de Orestes Guimarāes, em prover o ensino de um material didático específico para o ensino de português como segunda língua ou lingua estrangeira. Na obra Parecer sobre a Adopção de Obras Didacticas, apresentada por ele a Vidal Ramos em 1911, apenas são relacionados, para uso nos grupos escolares e escolas isoladas, livros de português como lingua materna, produzidos, naturalmente, por autores brasileiros. Obras da mesma natureza são novamente regulamentadas em 1928.

Apesar de considerar, nos objetivos e justificativa de seus programas, o português nas zonas coloniais como uma segunda lingua, Orestes Guimarães não adotou estratégias coerentes com essa visão. O que ele fez foi transportar as idéias de reforma do ensino do português como primeira lingua para o contexto da escola de clientela de lingua materna alemã. Em outras palavras, o programa desenvolvido por Orestes Guimarães objetivou para a minoria teuto-brasileira o monolingüismo na lingua dominante.

Resumidamente, a politica educacional dessa primeira campanha pode ser caracterizada como de submersāo e de forte tendência assimilacionista no nivel político-social. Através desse tipo de educação, o governo de Santa Catarina identificou, a exemplo de outros governos, o pluralismo cultural de sua população como indesejável e ameaçador à unidade do Brasil. 
LUNA, José Marcelo Freitas de. A política govemamental para o ensino de português a...

Ao analisarmos as experiências governamentais com o ensino da lingua portuguesa para os imigrantes durante a segunda campanha, percebe-se claramente que houve também uma tendência bastante forte, nāo só nos dispositivos legais mas também nas açōes das Ligas, à assimilação ou absorção dos imigrantes pela maioria lusobrasileira de forma imediata e opressiva.

Nesse contexto, a exposição exclusiva à lingua portuguesa serviu como forma de subjugação da lingua materna dos imigrantes. através da estratégia de redução da função dessa lingua para a comunidade. Ao não promover o ensino da lingua materna do aluno, nem tampouco permitir seu uso nas escolas, a politica educacional baseou-se em uma legislação que impôs proibiçāo explícita e ativa à lingua da minoria

A legislação brasileira e, em particular, a catarinense traduziram o mito de que os direitos de minorias representam uma ameaça à unidade nacional e à integridade territorial. Essa ideologia, comumente ilustrada pelo jargāo "uma lingua uma nação" (Mikes, 1986), reflete a visão de que a concessão de direitos lingüisticos e culturais leva à possibilidade de reivindicações maiores por autonomia e independência econômica e politica.

As açōes desenvolvidas no periodo em questão seriam hoje reconhecidas pela comunidade internacional como uma violação dos direitos humanos e um genocídio da lingua materna das comunidades teuto-brasileiras. Esse problema, também abordado como lingüicídio, é definido como:

Prohibiting the use of the language of the group in daily intercourse or in schools, or the printing and circulation of publications in the language of the group (Art. III da Convençāo contra Genocidio proposta para as Naçōes Unidas em 1948). (Citado em Skutnabb-Kangas \& Bucak 1995: 366).

O ensino de português, na Escola Teuto-Brasileira, define-se, no que diz respeito ao contexto brasileiro, por medidas que, se com- 
paradas isoladamente, podem ser caracterizadas como contraditórias. Por um lado, o Governo forneceu, por sua política de atraçāo do imigrante e pela falta de assistência escolar nas regiōes de colonizaçāo estrangeira, o clima favorável à geração e ao desenvolvimento do sistema de ensino teuto-brasileiro. Por outro lado, motivado por questōes político-econômicas de niveis regional, nacional e internacional, o Governo retirou, com a destruiçāo do sistema escolar teuto-brasileiro, de boa parte do nossa população ganhos educacionais e sociais significativos como, por exemplo, o bilingüismo e a consciência favorável ao pluralismo cultural.

\begin{abstract}
This article presents, based on primary sources, a discussion of the linguistic policy applied to the education of the GermanBrazilian children during the first four decades of the XX Century. The Brazilian context of the period is presented through the description of the Santa Catarina School System with a special emphasis on the two nationalization campaigns and the experiences with the teaching of Portuguese emerged from them in Santa Catarina State. The discussion is carried out through the perspective of the education and linguistic rights of the minorities.
\end{abstract}

KEY WORDS: Teaching of Portuguese; Historiography: German Immigrants; Linguistic Rights.

\title{
Bibliografia
}

AgUINO, I. (1942) Nacionalização do Ensino: Aspectos Políticos. Florianópolis: Imprensa Oficial do Estado.

GERTZ, R. (1987) O Fascismo no Sul do Brasil. Porto Alegre: Mercado Aberto. GUIMARÃES, O. (1911) Parecer sobre a Adopção de Obras Didacticas. Florianópolis: Gab. Typ. D'O Dia.

. Trecho de um Relatório (1918) Florianópolis: Officinas graphicas d'A Phenix. 
LUNA, José Marcelo Freitas de. A política governamental para o ensino de português a...

(1926) Programa de ensino das escolas isoladas das zonas coloniaes. (approvado pelo Decreto $n^{\circ} 1.944$ de 27 de fevereiro de 1926). Florianópolis: Officinas a elect. da Imprensa Official.

"FALA do Doutor Antonio Gonçalves Chaves". Primeira sessāo da vigésima quarta legislatura da Assembléia Provincial de Santa Catarina em 6 de outubro de 1882. Desterro, Typ. De José J. Lopes.

Jornal O Estado (22/01/38, 10/04/39, 02/05/40, 31/12/41, 21/08/42) Florianópolis.

RAMOS, S. (1939) A Colonização no Brasil. Porto Alegre: Typografia do centro S. A.

Relatório apresentado à Assembléia Legislativa Provincial de Santa Catarina pelo Presidente Francisco José da Rocha em 11 de outubro de 1887. Rio de Janeiro: Typ. União, 1888.

Relatório apresentado à Assembléia Legislativa Provincial de Santa Catharina na $2^{a}$ sessão de sua $26^{a}$ legislatura pelo Presidente Francisco José da Rocha em 11 de outubro de 1887. Rio de janeiro. Typ. Uniāo, 1888.

Relatório. Apresentado ao Dr. Manuel da Nóbrega, Diretor da Instrucção pública do Estado de Santa Catarina ao exmo Snr. Dr. Cid Campos, Secretario do Interior e Justiça, em 31 de maio de 1929. Florianópolis, 1929.

Relatório. Serviços da Instrução Pública durante o ano revolucionário (25 de outubro de 1930 a 25 de outubro de 1931) - apresentado pelo professor Barreiros Filho - Diretor.

SANTA CATARINA (1918) Officios da Instruçāo Pública à Secretaria Geral dos Negócios do Estado. São Bento.

SANTA CATARINA (1919) Minutas da Instrução Püblica 1918 e 1919. Florianópolis.

SANTA CATARINA (1940) Relatório apresentado ao Secretário de Estado dos Negócios do Interior e Justiça pelo Diretor Interino do Departamento de Educaçāo. Florianópolis.

SANTA CATARINA (1945) Instruções Liga Pró-Lingua Nacional. Departamento de Educação. Circulares 1943 -1944. Florianópolis: Imprensa Oficial do Estado.

Governo da República. Decreto-lei $n^{0} 868$ de 18 de novembro de 1938. In: LEX. Coletânea de Legislaçāo. Sāo Paulo: LEX. LTDA, 1938, p. 522-523.

Governo da República. Decreto-lei $n^{\circ} 1.006$ de 30 de dezembro de 1938. In: LEX. Coletânea de Legislaçāo. Sāo Paulo: LEX LTDA, 1939, p. 1-6. 
Governo da República. Decreto-lei $\mathrm{n}^{\circ} 3.580$ de 3 de setembro de 1941. In: LEX Legislação Federal, Estadoal e Municipal. São Paulo: LEX LTDA, 1941, 368-369.

SANTA CATARINA. Decretos, Leis, etc. Lei $n^{\circ} .1 .114$ de 30 de setembro de 1886. In: Coleçāo de decretos, leis e portarias de 1886. Florianópolis: Imprensa Oficial.

SANTA CATARINA. Decretos, Leis, etc. Decreto $\mathrm{n}^{\circ} .794$ de 2 de maio de 1914 In: Coleçāo de decretos, leis e portarias de 1914. Florianópolis: Imprensa Oficial.

SANTA CATARINA. Decretos, Leis, etc. Lei n. 1.187 de 5 de outubro de 1917. In: Colleção de Leis, Decretos, Resoluçōes e Portarias de 1917. Florianópolis: Officinas à elect. da Emprenza d'ODIA 1917, p. 77-81.

SANTA CATARINA. Decretos, Leis, etc. Decreto n. 1.063 de 8 de novembro de 1917. In: Colleçāo de Leis, Decretos, Resoluçōes e Portarias de 1917. Florlanópolis: Officinas à elect. da Empreza d' O DIA, 1917, p. 65-66.

SANTA CATARINA. Decretos, Leis, etc. Lei $\mathrm{n}^{\circ} 1.283$ de 15 de setembro de 1919. In: Coleção de decretos, leis e portarias de 1919. Florianópolis: Imprensa Oficial, 1919, p. 34-36.

SANTA CATARINA. Decretos, Leis, etc. Lei $\mathrm{n}^{\circ} 1.322$ de 29 de janeiro de 1920. In: Coleção de decretos, leis e portarias de 1920. Florianópolis: Imprensa Oficial, 1920, p. 21-23.

SANTA CATARINA. Decretos, Leis, etc. Decreto $n^{\circ} 58$ de 28 de janeiro de 1931. In: Coleção de Decretos, Resoluçōes e Portarias de 1931. Florianópolis: Gab. Tip. Brasil, 1932, p. 12-15.

SANTA CATARINA. Decretos, Leis, etc. Decreto Lei n. 35 de 13 de janeiro de 1938. In: Coleçāo de Decretos-leis de 1938. Florianópolis: Imprensa Oficial, 1938, p. 118.

SANTA CATARINA. Decretos, Leis, etc. Decreto-Lei n. 88 de 31 de março de 1938. In: Coleção de Decretos-Leis de 1938. Florianópolis: Imprensa Oficial, 1938, p. 119-129.

SANTA CATARINA. Decretos, Leis, etc. Decreto-Lei n. 124 de 18 de junho de 1938. In: Coleção de Decretos-Leis de 1938. Florianópolis: Imprensa Oficial, 1938, p. 119-129.

SANTA CATARINA. Decretos, Leis, etc. Decreto-Lei n. 301 de 24 de fevereiro de 1939. In: Coleção de Decretos-Leis de 1939. Floriantopolist Imprensa Oficial, 1939. p. 61-76. 
LUNA, José Marcelo Freitas de. A política govemamental para o ensino de português a...

SKUTNABB-KANGAS, T \& B. S. Killing a mother tongue - how the Kurds are deprived of linguistic human rights. In SKUTNABB-KANGAS, T. \& PHILLIPSON (Eds. ) Linguistic Human Rights: overcoming linguistic discrimination. Belin: Mouton de Gruyter, 1995, p. 347-370. 